\title{
Low-income sustainable dwelling
}

\author{
C. Cerro \\ College of Architecture, Art and Design, \\ American University of Sharjah, UAE
}

\begin{abstract}
Up to 100,000 people move into urban slums every day. According to UN-habitat, around $33 \%$ of the urban population in the developing world in 2012, or about 863 million people, lived in slums. The reasons for the growth of this urban phenomenon vary; from poor infrastructure, social exclusion and economic stagnation to colonialism and segregation. But at the core of the problem is a lack of dignified affordable housing. The low-income sustainable shelter was designed to address this issue and to start a conversation on dignified sustainable living. The unit is made out of stackable shipping containers. Each apartment can house a family of five or eight (depending on the amount of container used) people per floor, with a stackable capacity of five levels. All the elements are prefabricated in the slum itself, creating jobs for the community. The first floor is reserved for commercial use in an attempt to stimulate the economy of the area, the activity provided by the commercial spaces will also help in terms of security and safety. The top floor is an urban farm. The idea is to help the dwellers to have a passive source of energy, food and income. The unit combines both passive and active technologies to solve both economical and psychological problems that arise from dwelling in slums with the purpose of bringing back health, security, dignity and pride to these communities. Once the project is implemented the amount of green brought into the area will clean the air and will lower the cost of food by eliminating transportation costs, developing through all these systems, a better quality of life for the population of the slum.

Keywords: sustainability, green roofs, low-income housing, self-sufficiency, third nature, standard of living, health, containers, hydroponic farming, passive income.
\end{abstract}




\section{Introduction}

Slums all over the world are plagued with social, health and education problems but at the center of all of these issues we find one; low quality of life produced by substandard housing. In this paper I will present a solution to this problem by implementing high and low tech systems that when incorporated to the design environment can generate a 'third nature' in which sustainable smart housing combined with the production of food and energy can be used to redefine a housing typology for low-income areas. The paper will begin by defining the present issues to be addressed by the proposed dwelling unit design and will study the reuse of shipping containers as a feasible construction system for sustainable low-income housing. Then we will cover how sustainable solutions can be used to address the idea of a 'third nature' in marginal areas. Concluding with an explanation of the proposed units and how each of its elements will have a positive repercussion in the community using them.

\section{Third nature}

If we consider 'first nature' to be the natural world (wilderness) and 'second nature' to be the urban growth that has taken over the natural world, then 'third nature' can be defined as the point in which a sustainable man-made nature interacts with the built environment with a positive result as an outcome. This positive result comes from the hybridization of sustainable ideas with architecture to better the life of the user. 'Third nature' is then a new take on urbanism that provides an architecture that uses high tech and low tech systems to produce new typologies of urban elements that use sustainability as a default aspect of design, where solar panels are as expected in a building as is a door or a window. The result as in this project will provide us with an approach to design that is meant to attach the diversity of problems suffered by slum communities, from different perspectives and to ultimately better the standard of living of the user and his/her community.

\section{The problem}

According to the United Nations Human settlement program, for the first time in history, more than half the world's population live in cities: $54 \%$ in 2014 . In some cities more than $80 \%$ of the population lives in slums. By 2030, about 3 billion people ( $40 \%$ of the population of the planet), will need shelter and access to water, energy, food and sanitation (UN-Habitat [1]).

Despite the language of the Universal Declaration of Human Rights (art. 25.1) and the International Covenant on Economic, Social and Cultural Rights (art. 11.1), we can't consider the present housing situation in slums as a solution for the quality of life problem generated by the lack of appropriate shelter [2, 3]. In these slums, substandard dwellings and overcrowded conditions, lacking water and sanitation create health issues. And a lack of education and services prevent the upper mobility of the population. About half of all deaths in children under five 
years of age happen because of under nutrition, about three million children a year (UNICEF [4]). The architecture needed to fulfil our moral responsibility needs to be much more than just the creation of shelter, it need to increase the quality of life of the individual and the community.

\section{Shipping containers}

The project consists of reusing containers after the end of their life span as cargo units. A shipping container has a functional longevity of around 10 years. After that they are retired. In a lot of countries, retired containers are turned back into raw material or just stored. The storing of containers has created a surplus, which makes of the container, a cheap and in a lot of cases free resource. Each container is designed with a built in structural system capable of stacking 9 similar units (at full load) on top of the first one, solving simultaneously the structural and shelter aspects of the dwelling unit. The containers that will be used in the dwelling unit are designated by ISO as 1AAA (40 ft/12.1 m) and 1CCC (20 ft/6.058 m). Because the internal height of each of these containers is 2.7 meters, we are able to produce a housing unit with a usable height of 2.4 meters, which is an acceptable height in most construction codes. But let's be clear about something, no system is fully ecological nor is it fully sustainable. Even though the reuse of containers is in essence a good green solution, it does have problems. In Archdaily, Pagnotta points out that, "reusing containers seems to be a low energy alternative, however, few people factor in the amount of energy required to make the box habitable. The entire structure needs to be sandblasted bare, floors need to be replaced, and openings need to be cut with a torch or fireman's saw. The average container eventually produces nearly a thousand pounds of hazardous waste before it can be used as a structure" [5]. Having acknowledged these points, building with containers still remains a good sustainable solution for construction since it solves the essential pre requisites needed for the production of shelter at a minimum cost.

\section{The project}

Two side-by-side 20' containers (320 sq ft each) will stand for the base of the dwelling unit. This will be the commercial level. By bringing in small businesses to the ground level, we are guaranteeing street life, an economy to sustain the community and the safety that comes from having people on the street. The second level will be the first apartment unit. This unit will be composed of two side-byside 40' containers (640 sq ft each) welded together to produce a living unit for a family of 5. More containers can be added for expansion of the space. Offset from the center of the living unit there will be a bathroom and kitchen. All grey water will be taken to tanks for filtering and reusing. The rooms will consist in two pods with just enough space on them for sleeping in. The rest of the space will have an open plan. The walls of the unit will be insulated with aerogel ( $\mathrm{r}$ value $=10$ per inch.). The floors will be bamboo or reused lumber. The appliances will be energy efficient, running from electricity produced by solar panels on the roof. The dwelling can stack up to 5 units on top of the commercial one. Making the building 
height adaptable to the needs of the population. On top of the last residential unit there will be a shared garden level with hydroponic tubs for food production. The idea is to produce plants for the consumption of the unit and also to generate passive income for the dwelling. The vegetation will increase the quality of air in the community and since the garden is on top of the dwelling, it will serve as a thermal insulator for the rest of the building. The roof of the garden level will house solar panels and solar heaters. The different levels of the building will be connected by a vertical circulation tower that will house a stair. And it will also serve to house; a grey water tank, a filter and a clean water tank together with advanced air to water technology (Skywater distillation technology). Each building will be of the grid by producing its own energy, water and food. Organic trash will be consumed by worm farms that will then produce compost to help with the growth of fruits and vegetables at the green roof level. Human faeces will be composted to for use in non-consumable plans or to be sold to generate passive income. In this way, the dwelling unit will become a third nature system blending technologies and nature to create a sustainable, self-sufficient interdependent living unit, designed to improve the quality of life of those using it.

Figure 1 shows an exploded axonometric using the following key:

1. Oxygen producing plants will help control air quality.

2. The roof garden will have worm composting designed to help with the maintenance of the garden and to produce passive income to the building.

3. Reclaimed lumber will be used in all floors and panel systems.

4. Each unit will be energy smart and will use energy saving appliances and illuminating systems.

5. Solar batteries will be set under the hydroponic farm for energy storage.

6. Grey water storage and filtration systems will reside at the top of the circulation tower.

7. Solar water heater will be installed on the roof and connected to the building through the circulation tower.

8. Aerogel insulation will be used behind all interior walls. Aerogel has an R-value of 10 per inch.

9. Drinking water filtration systems will also reside in the circulation tower between the grey water tank and the clean water tank.

10. An atmospheric water generator will be set at the top of the circulation tower to produce water from the vapor in the air.

11. Each unit will be constructed by reusing shipping containers that have ended their commercial life.

12. Solar panels will be installed on the roof.

13. Hydroponic vertical farm tubes will be placed on the roof garden to produce food for the building and to create a passive income.

14. A prefabricated circulation system will be attached to the units to house water tanks, connect MEP systems and provide vertical circulation to the units. 


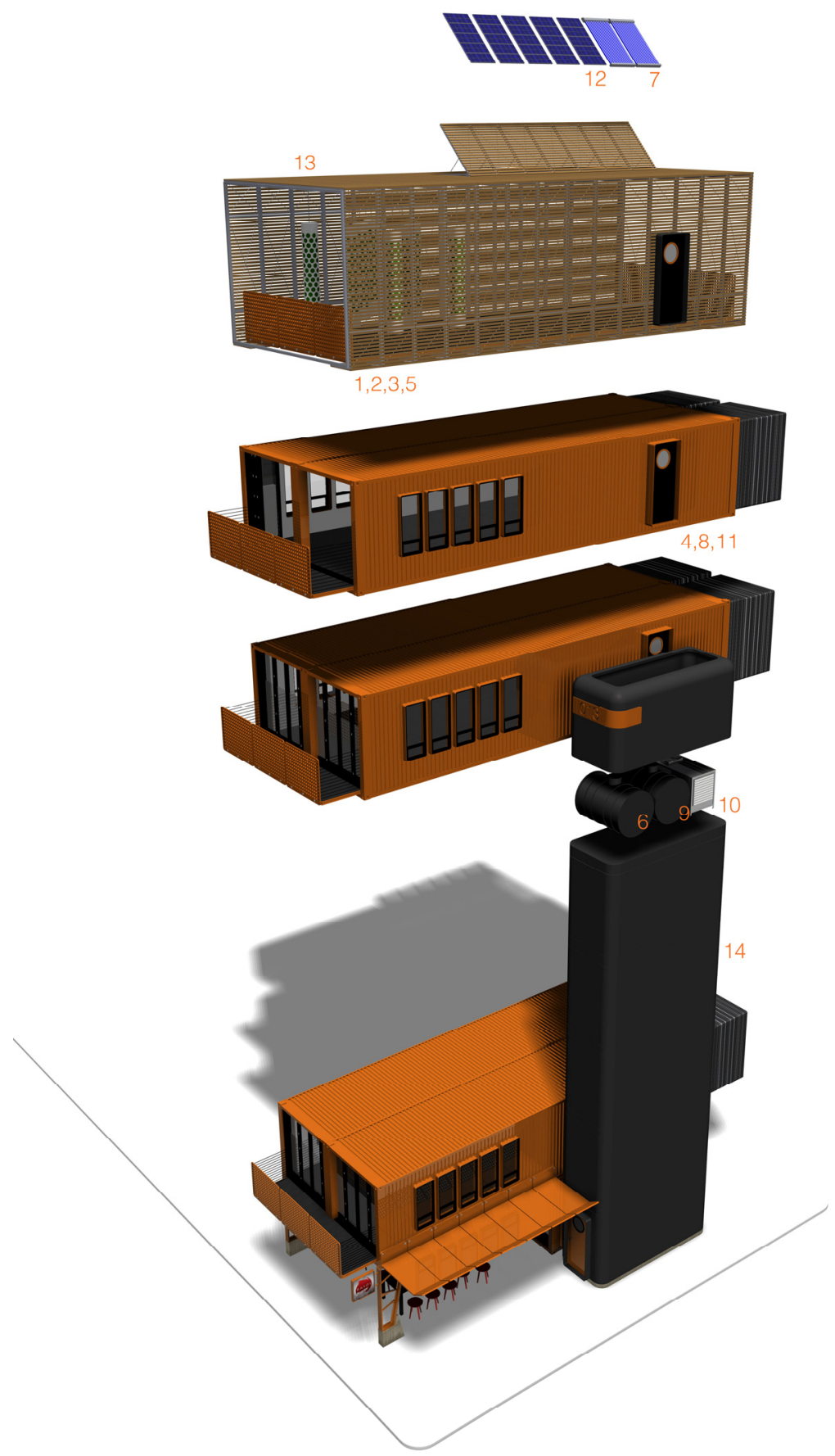

Figure 1: Exploded axonometric. 


\section{Developing economic growth}

The dwelling unit has been designed as a prefabricated system. All parts of the unit will be assembled in the community. By doing this we can provide jobs and technical education to those working on the project. This knowledge and training can be exported to other communities. As more people arrive to the community, more units will be produced and added vertically to the original buildings up to a maximum of five units (five stories are the maximum allowable height for a housing unit with no elevator). As the system is put in place, the same assembling process can be used to build supermarkets, hospitals, schools, etc. all produced with the same prefabricated components.

Modular projects can be problematic because of their repetitive nature and monolithic size. To confront this issue, the dwelling units have been designed with terraces on each level and a green garden on top to give the inhabitants the possibility of personalizing their space. The dwelling units are also small in nature, with capacity of expansion vertically and horizontally. And they will be placed close to each other to keep a scale that helps to preserve community through proximity.

"Although sustainable housing is often associated with wealth and affluence, it does not need to be so - genuinely sustainable houses are those that are inclusive and affordable for all. Addressing the issue of affordability is, therefore, a necessary condition for transformation towards sustainable housing. And yet affordability is not enough, because the so-called affordable homes cannot be considered sustainable if they create negative impacts on the environment or social life. The marriage of affordability with other sustainability conditions is a must" [1]. Which in the end is the essence for developing economic growth in these communities.

The unit will produce two other financial resources; it will have smaller commercial spaces on the ground level, designed for the developments of smallbusinesses. One of the biggest problems in slums is the lack of everyday items accessible to the population. This move is aimed at solving that problem by providing a place for the underground economies of the slum to happen and grow. The second resource is the potential to create passive income by the production of compost, fruits and vegetables, and energy, which can be sold to other parties or to the government so as to give the families a second source of income. Once some of the primary expenses of a family are taken out of the equation thanks to sustainable living, the family will find itself with extra money to better their present economic situation. In this manner the building has the potential to produce direct and indirect benefits to the economic life of the community.

\section{Conclusion}

In conclusion, this project is redefining our ideas of what we understand as a slum by transforming them into a landscape of opportunity where low income housing can be seen as a self-sufficient, sustainable dwelling system that is designed to help improve the economic, education and health of a community by its mere 
existence, producing a totally unique results: not entirely natural, and not entirely man made. A true third nature project designed to better the standard of living of its inhabitants. So that, "everyone has the right to a standard of living adequate for the health and well-being of himself and of his family, including food, clothing, housing and medical care and necessary social services, and the right to security in the event of unemployment, sickness, disability, widowhood, old age or other lack of livelihood in circumstances beyond his control (the Universal Declaration of Human Rights, art. 25.1 [2]).”

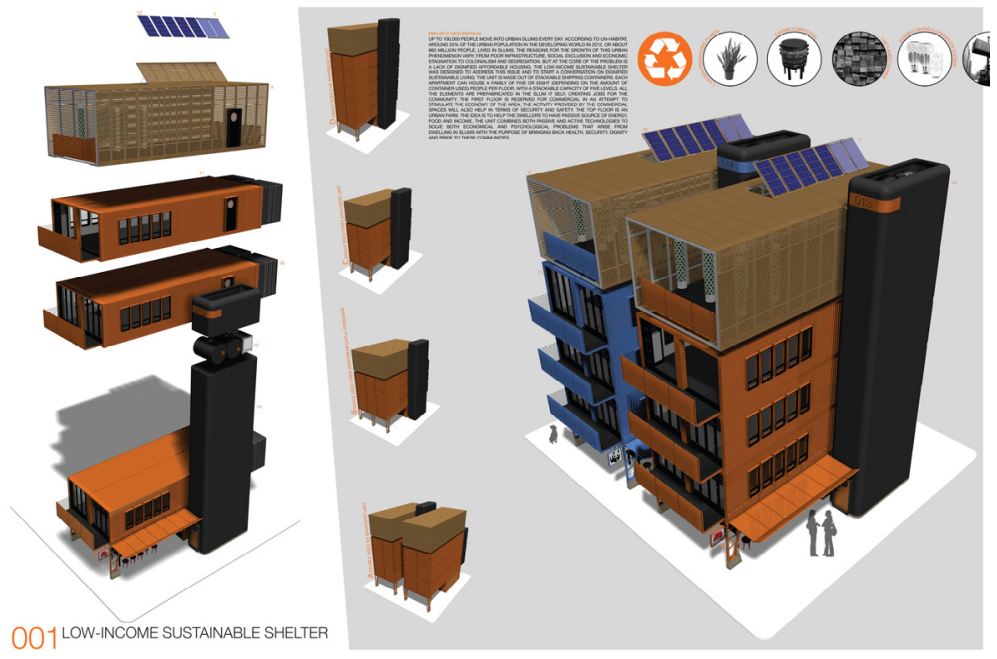

Figure 2: Display board one.

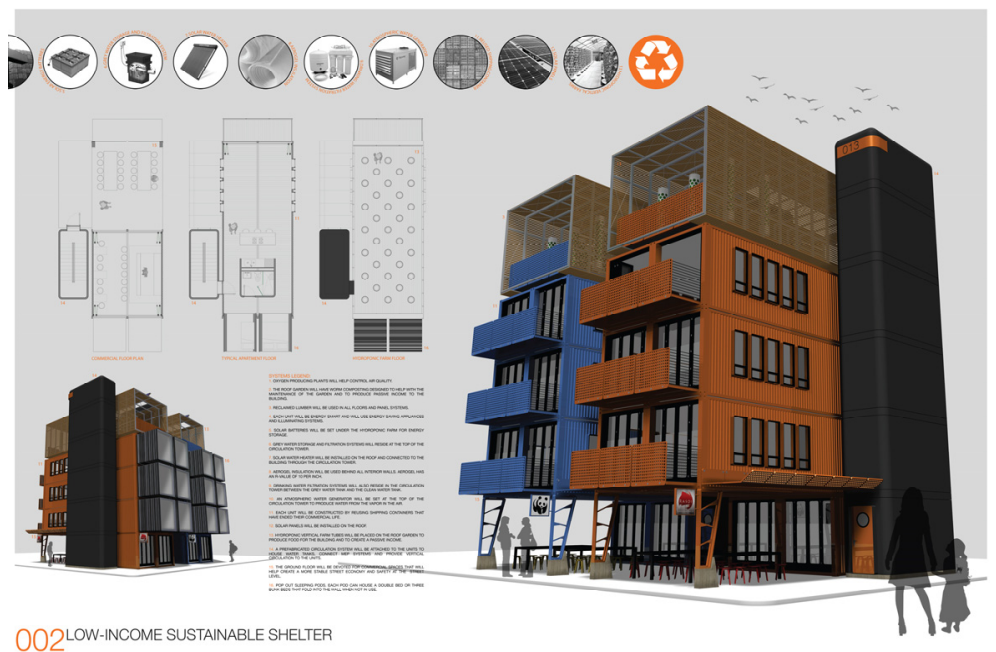

Figure 3: Display board two. 


\section{References}

[1] UN-Habitat (online). Available at: http://unhabitat.org/urban-themes/housing -slum-upgrading/. Accessed: May 29 2015.

[2] UN General Assembly, Universal Declaration of Human Rights, 10 December 1948, 217 A (III), article 25.1.

[3] UN General Assembly, International Covenant on Economic, Social and Cultural Rights, 3 January 1976, article 11.1.

[4] UNICEF. Available at: http://www.unicef.org/statistics/. Accessed: May $29^{\text {th }}$ 2015.

[5] Pagnotta, Brian (2011), The pros and cons of cargo container Architecture. http://www.archdaily.com/160892/the-pros-and-cons-of-cargo-containerarchitecture/. 